\title{
ES2012-91109
}

\section{ENERGETIC COMPARISON OF LINEAR FRESNEL AND PARABOLIC TROUGH COLLECTOR SYSTEMS}

\author{
Heiko Schenk \\ German Aerospace Center (DLR) \\ Institute of Technical Thermodynamics \\ 70569 Stuttgart, Germany \\ Jan Fabian Feldhoff \\ German Aerospace Center (DLR) \\ Institute of Solar Research \\ 70569 Stuttgart, Germany
}

\author{
Tobias Hirsch \\ German Aerospace Center (DLR) \\ Institute of Solar Research \\ 70569 Stuttgart, Germany \\ Michael Wittmann \\ German Aerospace Center (DLR) \\ Institute of Solar Research \\ 70569 Stuttgart, Germany
}

\section{ABSTRACT}

Within the last years, Linear Fresnel (LF) collector systems have been developed as a technical alternative to parabolic trough collector (PT) systems. In the past, LF systems focused on low- and medium temperature applications. Nowadays, LF systems equipped with vacuum receivers can be operated at the same temperatures as PT systems. Papers about the technical and economical comparison of specific PT and LF systems have already been published, [1-3]. However, the present paper focuses on the systematic differences in optical and thermodynamic performance and the impact on the economic figures

In a first step the optical performance of typical PT and LF solar fields has been examined, showing the differences during the course of the day and annually. Furthermore, the thermodynamic performance, depending on the operating temperature, has been compared.

In a second step, the annual electricity yield of typical PT and LF plants are examined. Solar Salt has been chosen as heat transfer fluid. Both systems utilize the same power block and storage type. Solar field size, storage capacity, and power block electrical power are variable, while all examined configurations achieve the same annual electricity yield. As expected for molten salt systems, both systems are the most cost-effective with large storage capacities. The lower thermodynamic performance of the LF system requires a larger solar field and lower specific costs in order to be competitive. Assuming specific PT field costs of $300 € / \mathrm{m}^{2}$ aperture, the break-even costs of the LF system with Solar Salt range between 202 and $235 € / \mathrm{m}^{2}$, depending on the site and storage capacity.

Keywords: linear Fresnel, parabolic trough, system comparison, solar thermal power plant, thermal energy storage, solar field cost, molten salt

$\begin{array}{ll}\text { NOMENCLATURE } \\ \text { CI } & \text { Capital Investment costs } \\ \text { COF }_{\mathrm{AF}} & \text { fraction of co-firing used for anti-freeze } \\ \text { COF }_{\text {el }} & \text { fraction of co-firing used for electricity } \\ \text { DNI } & \text { Direct Normal Irradiance } \\ \text { DSG } & \text { Direct Steam Generation } \\ \text { FLH } & \text { Full load Hours } \\ \text { IAM } & \text { Incident Angle Modifier (already includes } \\ & \text { cosine losses) } \\ \text { LF } & \text { Linear Fresnel } \\ \text { LCOE } & \text { Levelized Cost of electricity } \\ \text { O\&M } & \text { Operation and Maintenance } \\ \text { H\&P } & \text { Header and Piping } \\ \text { PB } & \text { Power Block } \\ \text { PT } & \text { Parabolic Trough } \\ \text { SF } & \text { Solar Field } \\ \text { SM } & \text { Solar Multiple } \\ \text { TES } & \text { Thermal Energy Storage } \\ A_{\text {net }} & \text { net aperture area of collector or field } \\ C_{\text {TES }} & \text { thermal capacity of storage in full-load hours } \\ C_{\mathrm{SF}, \mathrm{b}-\mathrm{e} .} & \text { break-even cost of (Fresnel) solar field } \\ P_{\text {gross }} & \text { gross electrical power of power block } \\ \dot{q}_{\text {solar }} & \text { area-specific optical power input to collector }\end{array}$




$\begin{array}{ll}\dot{Q}_{\text {solar }} & \text { optical thermal power of solar field } \\ \dot{Q}_{\text {loss }} & \text { thermal losses } \\ T_{\text {amb }} & \text { ambient temperature } \\ W_{\text {net }} & \text { annual net electricity output } \\ \alpha_{\mathrm{s}} & \text { elevation of the sun } \\ \eta_{\text {opt }, 0} & \text { optical efficiency at perpendicular irradiation } \\ & \text { on collector (PT and LF systems) } \\ \eta_{\text {opt }} & \text { current optical efficiency of collector system } \\ \eta_{\text {shad }} & \text { shading factor of collector rows in solar field } \\ \eta_{\text {end }} & \text { endloss factor for collector row } \\ \eta_{\text {clean }} & \text { cleanliness factor of mirrors } \\ \theta_{\mathrm{i}} & \text { incidence Angle (PT and LF systems) } \\ \theta_{\text {trans }} & \text { transversal angle of LF systems } \\ \rho_{\text {tr }} & \text { tracking angle of PT systems }\end{array}$

\section{INTRODUCTION}

Driven by the increasing activities in CSP technology within the last years, Linear Fresnel (LF) collector systems have been developed as a technical alternative to parabolic trough (PT) collector systems. While LF have been designed for lower temperature applications in the past, recent developments show that both line-focusing collector systems can, in principle, be used for the same thermodynamic process. Nevertheless, the different characteristics, especially optical performance, have to be considered for a decision for one of the systems. Although some studies about comparison of PT and LF applications, for example [1-3], have been published a comparison focusing on the systematic differences in energetic performance has not been conducted. It is the intention of this paper to provide, on the one hand, a methodology for a systematic comparison and, on the other hand, first results comparing LF and PT systems. Thus, in a first step, the methodology, applied for the comparison, is described. In a second step, the systematic differences between the two concepts will be worked out.

\section{METHODOLOGY}

The intention of the paper is to provide a systematic comparison of the two collector systems. Thus, we concentrate on keeping boundary conditions similar for both systems wherever possible. A stepwise analysis along the efficiency chain reveals the major differences between both systems and their impact for representative applications. At some points we introduce simplifications to make both systems comparable. We are aware that, after an optimization of the plant, the layout and thermodynamic parameters might be slightly different from the layouts we choose for this comparison. We consider the resulting deviations as small compared to the major differences between the two collector systems.

Furthermore, we follow the approach that both systems should by default deliver the same amount of energy per year. By varying solar field size, power block capacity, and storage capacity we identify a number of configurations that result in the same annual yield. Based on these thermodynamic calculations, some cost studies are presented that show the break-even costs of LF systems related to PT systems. We show that this break-even point is influenced by the application itself, thus we can derive a trend where LF systems have the highest advantage compared to PT systems. Recent tests results from PT as well as LF show that both systems are able to operate in the same temperature range. Thus, for the system comparison the same fluid cycle is assumed for both systems. The remaining difference is in the collector performance, namely the optical performance.

\section{DEFINITIONS}

Since PT and LF are both line-focusing systems, their heat balance can be described with the same set of equations.

The current optical efficiency of the solar field can be calculated with equation 1 .

$$
\eta_{\mathrm{opt}}=\eta_{\mathrm{opt}, 0} \cdot I A M \cdot \eta_{\text {shad }} \cdot \eta_{\text {end }} \cdot \eta_{\text {clean }}
$$

$\eta_{\mathrm{opt}, 0}$ describes the maximal optical efficiency at perpendicular incidence of sun rays on a perfectly clean mirror which is not shaded. The efficiency is by definition related to $A_{\text {net }}$. The IAM describes the reduction of the optical efficiency, in case of the PT system due to the incidence angle, and in case of the LF system due to the incidence angle and the transversal angle. The factor $\eta_{\text {clean }}$ describes the reduction of the optical efficiency due to soiling of mirrors. When the incidence angle is flat, in PT and in LF systems, optical end losses occur since at the collectors' ends a fraction of the reflected solar irradiation does not impinge on the receiver. Those losses are accounted for by the factor $\eta_{\text {end }}$ (for a definition see [1]). Furthermore, in parallel PT collector rows shading occurs when the sun's elevation is low (for a definition also see [1]). Shading in parallel LF rows, usually, either is neglected or integrated in the IAM function.

The effective specific optical input onto a solar field is described as $\dot{q}_{\text {solar }}$

$$
\dot{q}_{\mathrm{solar}}=\mathrm{DNI} \cdot \eta_{\mathrm{opt}}
$$

and the effective optical power as $\dot{Q}_{\text {solar }}$

$$
\dot{Q}_{\text {solar }}=\dot{q}_{\text {solar }} \cdot \mathrm{A}_{\text {net }}
$$

where $A_{\text {net }}$ represents the effective aperture area of the collector excluding gaps between mirrors.

In order to calculate the current thermal efficiency of the solar field $\eta_{\text {therm,field }}$ the effective current thermal power is related to the available optical power.

$$
\eta_{\text {therm,field }}=\frac{\dot{Q}_{\text {solar }}-\dot{Q}_{\text {loss,col }}-\dot{Q}_{\text {loss }, \mathrm{H} \& \mathrm{P}}}{\text { DNI } \cdot A_{\text {net }}}
$$

where $\dot{Q}_{\text {loss,col }}$ represents the heat losses of the receiver tube and $\dot{Q}_{\text {loss,H\&p }}$ the heat losses of all other pipes and equipment in the solar field. The numerator of the fraction represents the effective thermal power of the solar field and can be described as $\dot{Q}_{\text {field }}$.

In order to characterize the layout of a CSP power plant, the so-called solar multiple (SM) is often used. The SM 
describes the degree of over-sizing of the solar field in relation to the power block:

$$
\mathrm{SM}=\frac{\dot{Q}_{\text {field, nom }}}{\dot{Q}_{\mathrm{PB}, \text { nom }}}
$$

where $\dot{Q}_{\mathrm{PB}, \mathrm{nom}}$ represents the thermal input to the power block at its nominal operation point and $\dot{Q}_{\text {field,nom }}$ the thermal solar field power at nominal irradiation conditions. The definition of $\dot{Q}_{\text {field,nom }}$ is arbitrary, however usually a DNI of 800 to $900 \mathrm{~W} / \mathrm{m}^{2}$ at perpendicular irradiation and perfectly clean mirrors is chosen.

For example, while the SM of PT plants without thermal energy storage (TES) ranges between 1 and 1.4, plants with a significant storage capacity need an over-sized solar field in order to be able to charge the TES system. For example, the SM of a PT plant with a storage capacity of 8 full-load hours tends to range between 1.6 and 2. Note, that this range of SM is given in [4] for the plants using synthetic oil as heat transfer fluid. The cost structure of plants with molten salt as heat transfer fluid could shift these optima.

\section{REFERENCE SYSTEMS}

For the reference system, we have to define the thermodynamic cycle, the two collector types and the site.

\subsection{Thermodynamic cycle}

A number of different heat transfer fluids are discussed for the application in line-focusing plants. The state-of-the-art for PT is synthetic oil which limits operation temperatures to about $400{ }^{\circ} \mathrm{C}$. Direct steam generation (DSG) PT systems are ready to enter the market and a first commercial plant with steam parameters of $35 \mathrm{bar} / 340^{\circ} \mathrm{C}$ has gone into operation in Thailand by the end of 2011 [5]. DLR demonstrated collector operation at $500{ }^{\circ} \mathrm{C}$ in a Spanish test facility [6].

LF developers historically focussed on direct steam generation. First LF plants have been built in Spain by Novatec Solar with a saturated steam process at 55 bar [7]. The same company successfully tested its collector system for process temperatures up to $500{ }^{\circ} \mathrm{C}$, using a vacuum receiver tube similar to the one applied in PT [8]. From today's viewpoint, both, the LF and PT system, are ready to be operated up to high process temperatures. In order to make use of the inherent advantages of concentrating solar thermal power plants compared to photovoltaic electricity generation, the systems in focus are equipped with TES systems. The benefits of high process temperatures with attractive storage options are today represented by molten salt cycles. Although a number of technical challenges have to be solved, the technology appears to be promising. A molten salt cycle has been chosen for the present study for the following reasons:

- A technical solution for large storage sizes is available

- High temperatures around $500{ }^{\circ} \mathrm{C}$ can be reached
- Single-phase heat transfer fluid simplifies the system comparison

- There are fewer restrictions regarding maximum and minimum charge and discharge rates of the storage system. These are mainly defined by the solar field and power block.

- There is no major difference between solar field and storage operation points (compared to oil-based systems where in storage mode the power block is operated at reduced load)

\subsection{Parabolic Trough Reference System}

PT systems are the most mature technology for CSP. The first SEGS plants in the US were equipped with LS-1 collector design. The increase in aperture area led to higher concentration factors. Collector types LS-1 to LS-3 have already been installed in the SEGS plants, respectively. The aperture width of $5.76 \mathrm{~m}$ developed into a kind of standard that was used by many collector manufacturers for the come-back of CSP in Spain (Flagsol, Sener, Acciona, Enea, Solel, Abengoa). A typical representative is the Eurotrough collector. Further cost reduction was achieved by increasing the collector lengths, i.e. the length of one collector unit that is moved by a single drive. The SKAL-ET collector dimensions are a kind of standard in collector technology, up to date, although we see a number of different construction concepts. The construction concept influences the peak optical efficiency of the system and the stiffness against torsion and wind load. In the past years approaches to larger aperture width and collector length have been taken by a number of companies. However, these concepts have not been realized in commercial plants, yet. A comprehensive review on different collectors is available from [9].

The performance data of these collector systems mainly differ in terms of peak optical efficiency. Effects like end-losses and shading are defined by the collector geometry, and thus are similar for all collectors. For the comparison in this paper thus refers to a SKAL-ET class collector since performance data are publically available [10]. The optical performance of the collector is expressed with the so-called Incidence Angle Modifier (IAM) which depends on the incidence angle $\theta_{\mathrm{i}}$ and is very similar for most of the PT collectors. The IAM of the SKAL-ET, in which cosine losses already are included, is plotted in Fig. 4.1.

Today, collector manufacturers make use of commercially available receivers. At the moment, Schott Solar CSP and Siemens-Solel dominate the market. Other suppliers like Archimede and Huiyin enter the market. Recent development shows that the performance of the receivers is quite similar. Therefore, the Schott's PTR 70 serves as reference for this comparison, [11]. Whereas the commercial version allows operating temperatures up to $450^{\circ} \mathrm{C}$, [12], in the REAL-DISS project, a modified version of the receiver was adapted to operating temperatures up to $500{ }^{\circ} \mathrm{C}$, [6]. 
Relevant performance parameters are shown in Table 4.1. At nominal conditions $(850 \mathrm{~W} / \mathrm{m} 2$ at perpendicular incident, $500{ }^{\circ} \mathrm{C}$ ) an optical input of $3.3 \mathrm{~kW} / \mathrm{m}$ is attained. For evaluating the plant performance we also need to define the layout of the collector field. We define the collector axis to be aligned in north-south direction. In the present study the collector shall have a similar shape as in state-of-the-art oil-based plants, where a loop consists of 4 collectors with a total receiver length of $600 \mathrm{~m}$. The distance between two collector rows (centre to centre) is set to three times the aperture width.

Table 4.1: Parameters of PT collector and solar field

\begin{tabular}{|l|c|}
\hline collector type & Skal-ET \\
\hline aperture width / length & $5.8 \mathrm{~m} / 150 \mathrm{~m}$ \\
\hline net aperture area collector & $817.5 \mathrm{~m}$ \\
\hline number of collectors per loop & 4 \\
\hline focal length & $1.71 \mathrm{~m}$ \\
\hline row distance (centre to centre) & $3^{*}$ aperture width $=17.3 \mathrm{~m}$ \\
\hline orientation & north-south \\
\hline $\begin{array}{l}\text { peak optical efficiency (related } \\
\text { to net aperture area) }\end{array}$ & $78 \%$ \\
\hline incident angle modifier (IAM) & according to [10], \\
& see Fig. 4.1 \\
\hline outer diameter of absorber tube & 70 mm \\
\hline $\begin{array}{l}\text { receiver type / } \\
\text { heat losses of receiver }\end{array}$ & $\begin{array}{c}\text { Schott PTR 70 } \\
\text { according to [1]] }\end{array}$ \\
\hline heat transfer fluid & Solar Salt \\
\hline
\end{tabular}

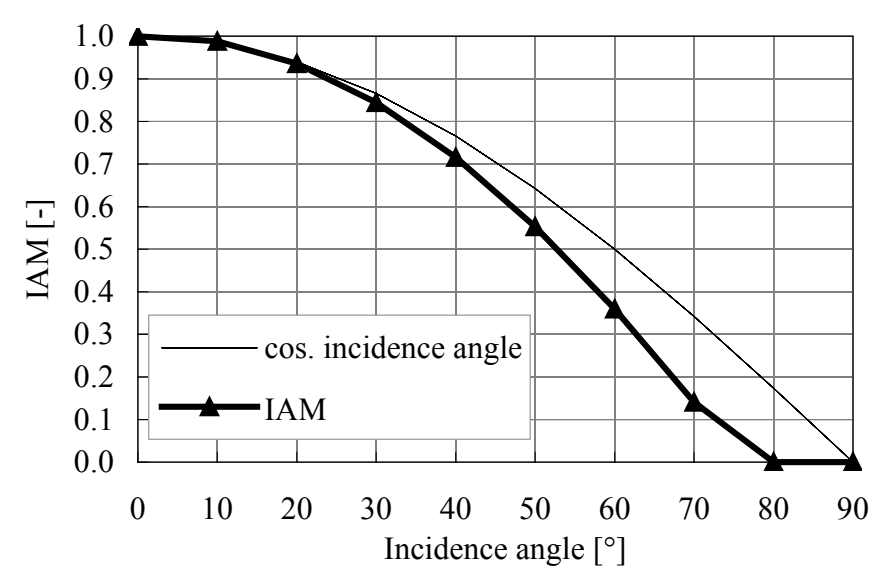

Figure 4.1: Cosine of incident angle and IAM of the PT collector

\subsection{Linear Fresnel Reference System}

The idea of a fixed absorber tube and facetted mirrors led to the development of the Linear Fresnel technology. There are two collector concepts currently being realized in commercial plants. One is by Novatec Solar and the other by Areva Solar [13]. Some other concepts have been followed by Solar Power
Group [14]. For the technology comparison we will refer to the Novatec system NOVA-1, since reliable performance data is publically available [15]. The NOVA-1 collector has proven its reliability in the PE-1 (Puerto Errado) test plant in Spain. The test plant consists of two rows of 18 collector modules each with a total length of $806.4 \mathrm{~m}$, producing saturated steam up to 55 bar $/ 270{ }^{\circ} \mathrm{C}$. The collector system consists of the fixed absorber tube equipped with a secondary reflector and a total of 16 mirror rows which yield a net aperture area of $513.6 \mathrm{~m}^{2}$ per collector module. The length of one module that is moved by one drive unit is $44.8 \mathrm{~m}$.

The commissioning of the first commercial $30 \mathrm{MW}$ plant PE-2, using the same collector, is under way. While a saturated steam system $(55$ bar) is realized there, a test loop with improved concept has recently shown applicability for temperatures up to $500^{\circ} \mathrm{C}$. The so-called SUPERNOVA system will make use of standard vacuum receivers similar to the PT, [8]. In the present study, the use of molten salt as heat transfer fluid will allow working temperatures up to $500{ }^{\circ} \mathrm{C}$, hence, the considered solar field will entirely consist of the new generation of PT collectors with vacuum receiver.

Due to the use of a vacuum receiver, the optical efficiency of the collector decreases by 2 to $3 \%$, [7], while the IAMcharacteristics remain similar to the ones of the NOVA-1 collector. The IAM is expressed as a product of a transversal and a longitudinal component according to [15]:

$$
\operatorname{IAM}=\operatorname{IAM}_{\text {trans }}\left(\theta_{\text {trans }}\right) * \operatorname{IAM}_{\text {long }}\left(\theta_{\mathrm{i}}\right)
$$

and is plotted in Fig. 4.2. A definition of angles can be found in [1].

In Table 4.2, the collector and solar field parameters, which are considered in the present study, are summarized.

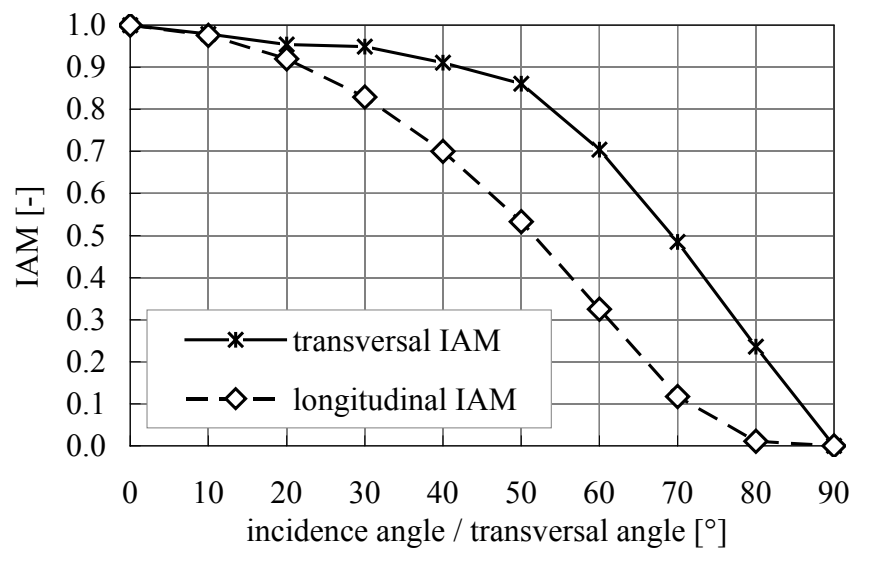

Figure 4.2: Longitudinal and transversal IAM of the LF collector

At nominal conditions $(850 \mathrm{~W} / \mathrm{m} 2$ at perpendicular irradiation, $500{ }^{\circ} \mathrm{C}$ ) an optical input of $6 \mathrm{~kW} / \mathrm{m}$ is attained which is about $81 \%$ higher than that of the PTC. 
Table 4.2: Parameters of LF collector and solar field

\begin{tabular}{|l|c|}
\hline collector type & SUPERNOVA \\
\hline module length / width & $44.8 \mathrm{~m} / 16.7 \mathrm{~m}$ \\
\hline net aperture area of module & $513.6 \mathrm{~m}^{2}$ \\
\hline number of modules per collector & 13 \\
\hline length of collector & $582.4 \mathrm{~m}$ \\
\hline focal length & $7.4 \mathrm{~m}$ \\
\hline number of collectors per loop & 1 \\
\hline row distance (centre to centre) & $21.5 \mathrm{~m}$ \\
\hline orientation & north-south \\
\hline $\begin{array}{l}\text { peak optical efficiency (related to } \\
\text { net aperture area) }\end{array}$ & $65 \%$ \\
\hline average mirror cleanliness & $98 \%$ \\
\hline incident angle modifier (IAM) & according to [15], \\
& see Fig. 4.2 \\
\hline outer diameter of absorber tube & 70 mm \\
\hline $\begin{array}{l}\text { receiver type / } \\
\text { heat losses of receiver }\end{array}$ & $\begin{array}{c}\text { Schott PTR 70 } \\
\text { according to [11] }\end{array}$ \\
\hline heat transfer fluid & Solar Salt \\
\hline
\end{tabular}

\subsection{Further technical and site data}

Two reference sites have been chosen: Daggett, California, US and Seville, Spain. Irradiation data for Daggett is publically availably [16] whereas the data for Seville has been generated with the commercial software Meteonorm [17]. Characteristic data for both sites is shown in Table 4.3

Table 4.3: Metrological data of Daggett and Seville

\begin{tabular}{|l|c|c|c|}
\hline & unit & Daggett (CA, US) & Seville (Spain) \\
\hline latitude / longitude & {$\left[{ }^{\circ}\right]$} & $34.85 /-116.8$ & $37.4 /-5.98$ \\
\hline annual DNI sum & {$\left[\mathrm{kWh} / \mathrm{m}^{2}\right]$} & 2724 & 1881 \\
\hline mean / min / max. & {$\left[{ }^{\circ} \mathrm{C}\right]$} & $16.3 /-5.0 /$ & $18.3 / 2.3 /$ \\
temperature & & 46.7 & 40.5 \\
\hline
\end{tabular}

The solar fields of PT and LF systems are already described in sections 4.2 and 4.3. All further important plant parameters can be found in Table 4.4. As heat transfer fluid in the solar field and in the sensible two-tank storage system Solar Salt $(60 \% \mathrm{NaCO}, 40 \% \mathrm{KNO} 3)$ is chosen since it represents the commercial molten salt solution until today. The utilization of molten salt in parabolic troughs, as well as the thermophysical properties are discussed in [18]. The minimal operating temperature in the plant is set to $260{ }^{\circ} \mathrm{C}$ in order to avoid crystallization.

For both systems the nominal operating point is set to a DNI of $850 \mathrm{~W} / \mathrm{m}^{2}$ (perpendicular incidence), which serves as reference for the solar multiple (see equation 5).

The losses of the solar field headers and piping $\dot{Q}_{\text {loss,H\&P }}$ occur at nominal operating temperature of the solar field. In the present study we assume that the heat losses of PT system are about twice as high as the ones of the LF system. This is due to the fact that the LF system consists of a smaller number of loops and furthermore, no flexible pipe connections are necessary (as in the PT system), which further reduces heat losses.

Table 4.4: Plant specifications

\begin{tabular}{|c|c|c|c|}
\hline & unit & PT & LF \\
\hline nominal $\dot{q}_{\text {solar }}$ & {$\left[\mathrm{W} / \mathrm{m}^{2}\right]$} & \multicolumn{2}{|c|}{850} \\
\hline nominal $T_{\text {amb }}$ & {$\left[{ }^{\circ} \mathrm{C}\right]$} & \multicolumn{2}{|c|}{20} \\
\hline $\begin{array}{l}\text { specific heat loss of SF } \\
\text { headers and piping } \\
\text { related to } A_{\text {net }}\left(\dot{Q}_{\text {loss,H\&P }}\right)\end{array}$ & {$\left[\mathrm{W} / \mathrm{m}^{2}\right]$} & 15 & 7.5 \\
\hline $\begin{array}{l}\text { SF inlet / outlet } \\
\text { temperature }\end{array}$ & {$\left[{ }^{\circ} \mathrm{C}\right]$} & \multicolumn{2}{|c|}{$290 / 500$} \\
\hline Heat transfer medium & & \multicolumn{2}{|c|}{ Solar Salt } \\
\hline Anti-freeze temperature & {$\left[{ }^{\circ} \mathrm{C}\right]$} & \multicolumn{2}{|c|}{260} \\
\hline $\begin{array}{l}\text { land use factor } \\
\text { (related to } A_{\text {net }} \text { ) }\end{array}$ & {$[-]$} & 3.5 & 2 \\
\hline solar multiple SM & & \multicolumn{2}{|c|}{$1.2 \ldots 3$} \\
\hline PB gross efficiency & {$[\%]$} & \multicolumn{2}{|c|}{42} \\
\hline PB nominal gross power & [MW] & \multicolumn{2}{|c|}{$20 \ldots 100$} \\
\hline $\begin{array}{l}\text { minimum, maximum } \\
\text { thermal PB load }\end{array}$ & {$[\%]$} & \multicolumn{2}{|c|}{$15 / 102$} \\
\hline storage type & & \multicolumn{2}{|c|}{ direct two tank Solar Salt } \\
\hline $\begin{array}{l}\text { temperatures of hot / } \\
\text { cold storage tank }\end{array}$ & {$\left[{ }^{\circ} \mathrm{C}\right]$} & \multicolumn{2}{|c|}{$500 / 290$} \\
\hline storage capacity ${ }_{C T E S}$ & {$[\mathrm{FLH}]$} & \multicolumn{2}{|c|}{$2,4,6,8,10,12,14$} \\
\hline $\begin{array}{l}\text { max. annual fossil co- } \\
\text { firing }\end{array}$ & {$[\%]$} & \multicolumn{2}{|c|}{$\begin{array}{c}15 \\
\text { (as in Spain) }\end{array}$} \\
\hline
\end{tabular}

The size of the SF, the gross power of the $\mathrm{PB}$ and the number of FLH of TES will be varied (see section 7). Note that the storage capacity is related to the number of FLH of the power block. Hence, solutions with constant storage capacity in FLH do not have the same capacity in MWh. In molten salt systems the storage system tend to be less expensive and more efficient than in thermal oil plants, since no heat-exchangers are necessary. Hence, molten salt plants without TES tend to be less economical and are not considered in the present study

Wet cooling conditions are assumed for the power block. Its gross efficiency is set to $42 \%$. The allowed co-firing is defined as the fuel equivalent that is necessary to produce $15 \%$ of the generated electricity of the plant.

\section{OPTICAL PERFORMANCE}

In the first step we compare the optical efficiency of the PT and LF systems. There is an inherent difference between the peak optical efficiency which is higher for the PT system (see sections 4.2 and 4.3 ).

The tracking angle of the PT system corresponds to the transversal angle of the LF system $\left(\theta_{\text {trans,LF }}=\rho_{\text {tr,PT }}\right)$. While the optical performance of a PT solar field is only affected by high tracking angles (which correspond to very low sun heights - see curve for $\rho_{\text {tr }}=80^{\circ}$ in Fig. 5.1) due to shading between collector rows, the optical performance of a LF system strongly depends 
on the transversal angle $\theta_{\text {trans. Thus, the LF system }}$ systematically collects less energy at low sun heights. The reason is that the primary reflectors of the LF have to be designed for a certain transversal angle. For all other transversal angles the curvature of the mirror panels is not optimal. In contrast, the parabolic shape of the PT mirror surface is the optimum reflecting surface independent of the track angle. However, optical end losses occur in PT as well as in LF solar field

Fig. 5.1 shows the optical efficiency of a LF and a PT solar field over the incidence angle $\theta_{1}$ for different transversal angles $\theta_{\text {trans }}\left(\right.$ or $\rho_{\text {tr }}$ respectively). From here, it becomes clear that the LF system shows minor performance, especially for high transversal angles.

Fig. 5.2 and 5.3 show the sorted distribution of the DNI, the IAM-corrected DNI, and the specific optical input, $\dot{q}_{\text {solar }}$ for both sites. By comparing both sites it becomes clear that the maximal DNI in Daggett is higher than the one in Seville, and also there are more annual hours with direct solar irradiation. By observing the curves for $\dot{q}_{\text {solar }}$ there is a significant offset between the LF and the PT system, which is due to the lower optical efficiency.

The curve of the IAM-corrected DNI shows that the LF system is already penalized by its IAM-characteristics. Hence, by over-sizing a Fresnel field similar nominal optical power can be attained, but the IAM-characteristics would still lead to more operation hours in part-load and to probably less operating hours per year.

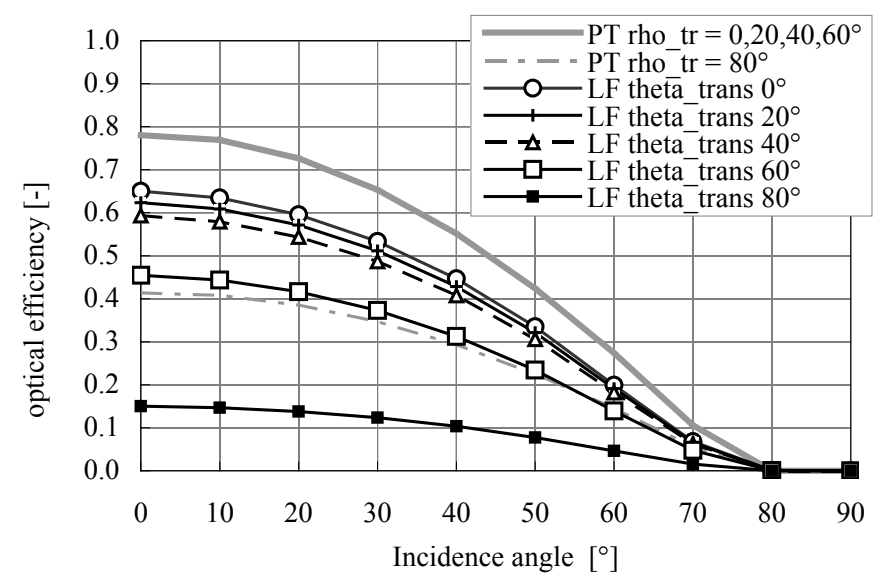

Figure 5.1: Optical efficiency of PT and LF system including field losses (shading and end losses)

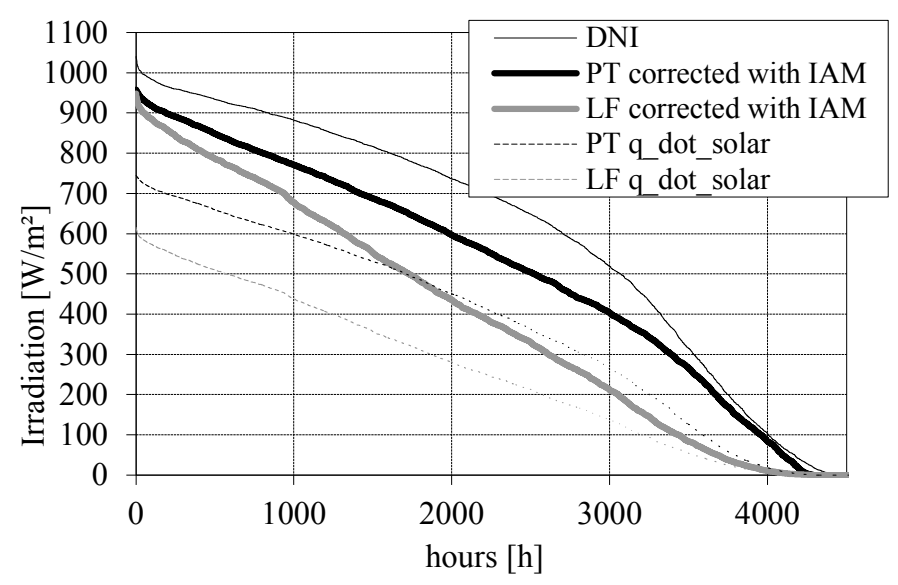

Figure 5.2: Annual distribution of DNI, IAM-corrected DNI, and area-specific optical input for Daggett

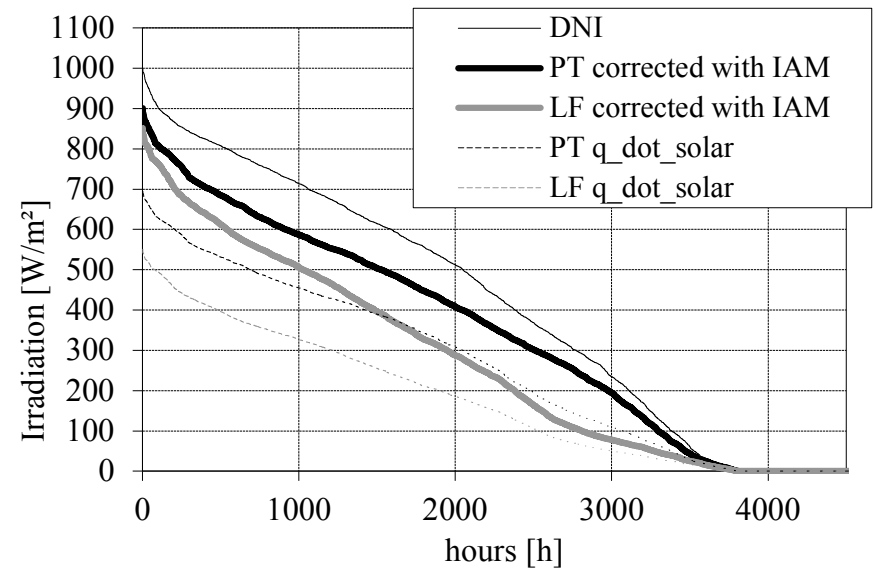

Figure 5.3: Annual distribution of DNI, IAM-corrected DNI, and area-specific optical input for Seville

As representative examples the optical performance of the LF and PT systems are evaluated for three clear-sky days, one typical winter day close to winter solstice, one day close to equinox, and one day in the summer season in Daggett (December 12, March 20, and June 21). Fig. 5.4 shows the DNI and the elevation of the sun $\alpha_{\mathrm{s}}$. As visible, the maximal DNI on a clear-sky winter day (December 12) can be as high as in summer and higher than on the day in March at this site. However, the energy yield of both systems, LF and PT, will be lower in winter than in summer due to two phenomena:

- The duration of the day is shorter

- The lower sun elevation $\alpha_{\mathrm{s}}$ leads to greater incidence angles for both systems and to greater transversal angles for the LF system, which diminishes the optical performance (compare with Fig. 5.1)

The optical efficiencies of both systems for the three exemplary days are shown in Fig. 5.5. Fig. 5.6 shows the optical power input $\dot{q}_{\text {solar }}$ of both systems. By observing the PT system 
it becomes clear that the optical efficiency is higher in the morning and evening than on solar noon which is typical for north-south-oriented PT systems. In combination with the daily evolution of the DNI (which attains its maximum at solar noon) a wide plateau of almost constant optical yield is attained. In contrast, the optical efficiency of the Fresnel system attains its peak at solar noon entailing a midday peak of solar power, in summer. On the winter day and the day close to equinox, $\dot{q}_{\text {solar }}$ can also be described as a plateau which is, nevertheless, much shorter than the one of the PT system.

For an efficient use of a power cycle the PT system is in favor, since the number of part-load operating hours is smaller. For a LF system the power block must either be designed larger or a serious amount of thermal energy must be dumped during the overload periods. Furthermore, independently from the dimensions of the solar field, the operating period with relevant output is shorter for the LF system.

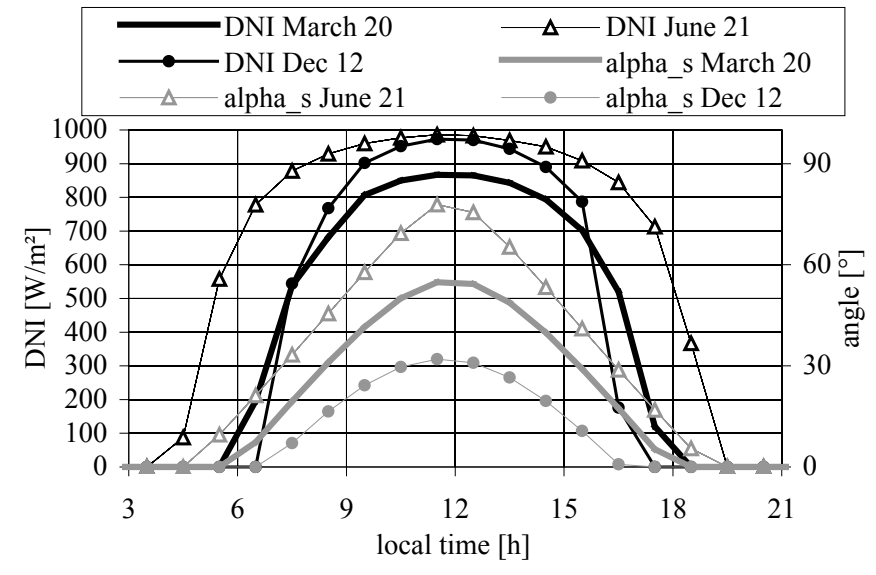

Figure 5.4: DNI and sun elevation $\alpha_{\mathrm{s}}$ March 20, June 21, Dec. 12 for Daggett

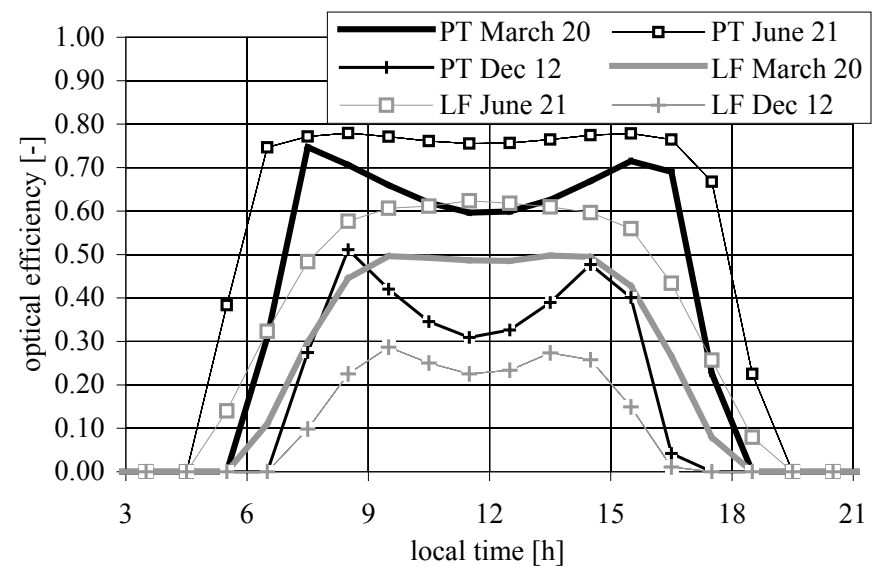

Figure 5.5: Optical efficiency of a PT and LF system solar field on March 20, June 21, December 12 for Daggett

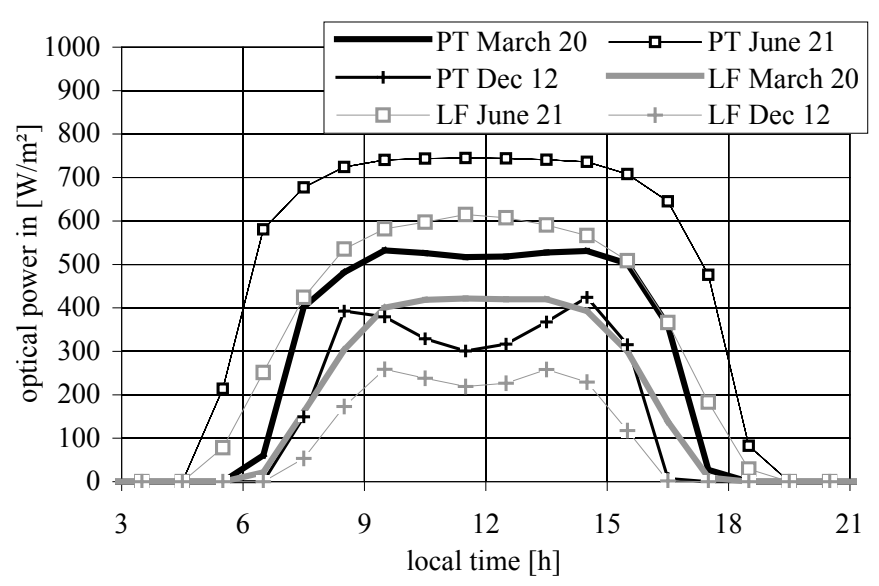

Figure 5.6: Optical power ( $\left.\dot{q}_{\text {solar }}\right)$ of a PT and LF system solar field on March 21, June 21, December 21 for Daggett

\section{THERMAL PERFORMANCE}

While the optical performance is the main difference between LF and PT, the heat loss characteristics are quite similar since the same receivers are installed. Nevertheless, in the Fresnel system there are less running meters of receiver tubes, and furthermore, the specific heat losses of headers and piping are lower (compare with section 4.4). Hence, the areaspecific heat losses (receivers and piping together) are lower in the LF system than in the PT system, see Fig. 6.1. Fig. 6.2 shows the thermal efficiency $\eta_{\text {therm,field }}$ (equation (4), section 3 ) of both systems for two different DNI (perpendicular irradiation) over the difference between ambient and fluid temperature. Although the Fresnel system heat losses are lower, they cannot compensate the inferior optical performance. Nevertheless, the differences in curvatures indicate that the Fresnel system is more tolerant against higher process temperature.

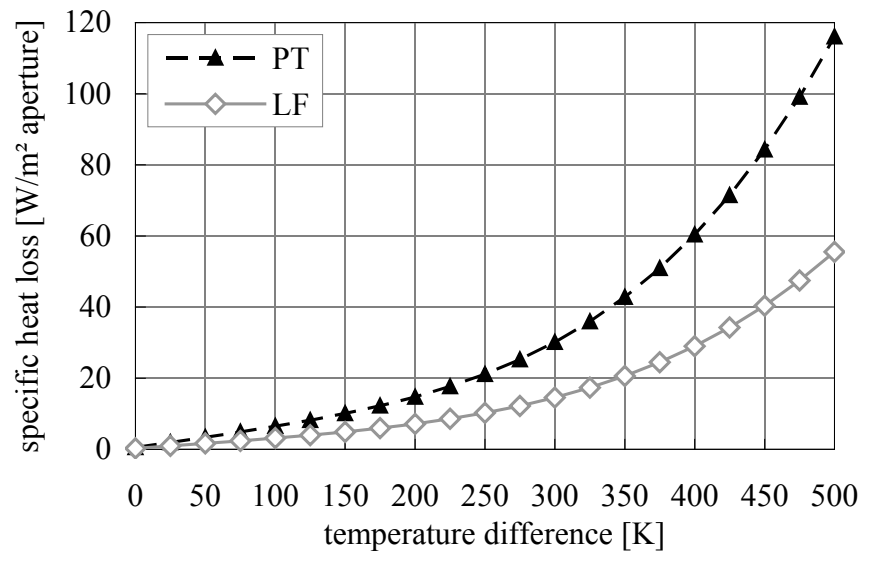

Figure 6.1: Specific heat losses of the collector systems 


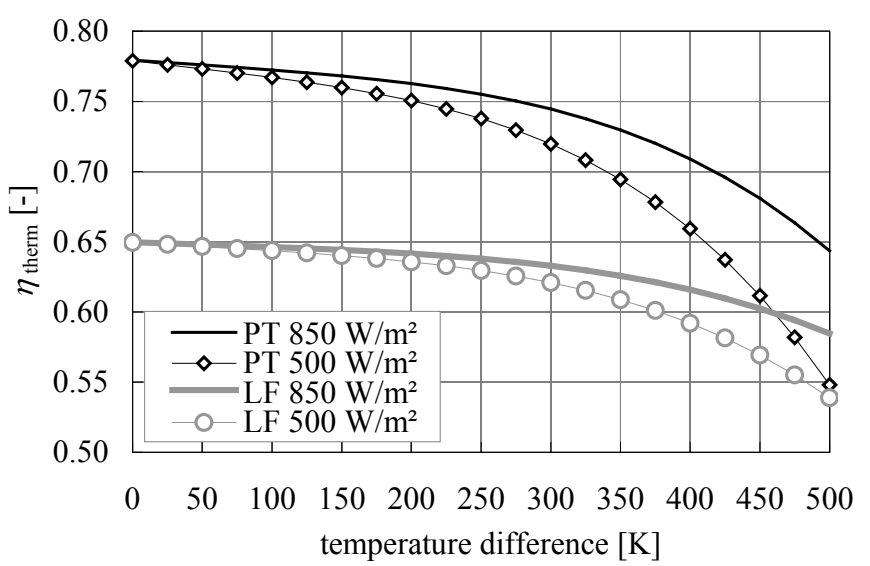

Figure 6.2: Thermal efficiency of collector field at $\mathrm{DNI}=850 \mathrm{~W} / \mathrm{m}^{2}$ and $500 \mathrm{~W} / \mathrm{m}^{2}$ (perpendicular irradiation)

\section{PLANT PERFORMANCE}

\subsection{Description of thermodynamic plant model}

The thermodynamic results of the present study have been generated with a DLR-internal steady-state thermodynamic model which is based on energy flows. The model is able to calculate annual energy yields of line-focussing CSP plants with typical heat transfer fluids such as thermal oil, water/steam, and molten salt. Since the model is very fast, parameter variations can be carried out comfortably. In spite of the steady-state approach thermal masses of the plant components are implemented in the model, in order to take into account energetic efforts of cool-down and start-up procedures. A simple solar-driven operating strategy is implemented. After sunset, the PB is operated in full load until the TES is discharged. When the solar field attains its minimal temperature, anti-freeze operation is provided by fossil co-firing. The remaining allowed annual co-firing energy ( $15 \%$ in this case) is used to produce more electrical energy.

\subsection{Assumptions}

Analysis of the plant performance requires the definition of some more boundary conditions. The general approach is to compare configurations that generate the same annual net electrical output $W_{\text {net }}$. Furthermore, systems with a large range of storage capacities (0..14 FLH) shall be compared. Having the thermodynamic process parameters fixed, the plant layout is defined by three major design values:

- solar field size $A_{\text {net,SF }}[\mathrm{m} 2]$

- power block nominal gross power $P_{\mathrm{el}, \text { gross }}[\mathrm{MW}]$

- storage capacity $C_{\mathrm{TES}}[\mathrm{FLH}]$

The SM is derived from $A_{\text {net }}$ and $C_{\mathrm{TES}}$. Having in mind the differences in the daily output of PT and LF it would not be fair to compare systems with the same annual output and at the same time define the same power block capacity for both systems
(For a LF system, the optimum power block capacity might be different from the one of the PT). Provided values for two of the three major design values, the third one is always given from the condition of equal annual output. We make a further assumption that for the configurations considered (a certain annual output, a certain storage capacity in FLH) the specific performance of the three main components is not affected by their size. This means e.g. that the gross efficiency of the power block is the same for a turbine with $50 \mathrm{MW}$ and $60 \mathrm{MW}$. Although larger components tend to be more efficient, this assumption appears to be appropriate for this study. We can then relate the component sizes relative to each other in terms of

- solar multiple (SM)

- full load hours (FLH) of the TES system

In that manner, we can compare PT and LF configurations with various combinations of solar field size, power block electrical power and storage capacity that all yield the same annual output. In a second step an economic optimization is carried out in order to find the cost-optimized configurations for each category of storage capacity.

\subsection{Economic analysis}

Since the thermodynamic process is the same for both systems we can assume the same specific power block and storage investment costs. The significant difference is in the specific solar field costs which are announced to be significantly lower for the LF than for the PT system (if related to aperture area). In contrast to previous publications [2], [1] the present paper avoids comparing PT and LF systems in terms of LCOE (levelized cost of electricity). In order to do so the following assumptions are made:

- The O\&M (operation and maintenance) costs of both systems are equal

- Due to different operating times of the set of presented solutions, the offline parasitics might slightly differ. However, this difference is neglected

- The price of sold electricity not variable (constant feed-in tariff), hence, the daily repartition of $W_{\text {net }}$ does not have an economic impact.

Since all examined solutions provide the same $W_{\text {net }}$ they can be compared by their capital investment costs (CI). From the $\mathrm{CI}$ the break-even costs $C_{\mathrm{SF} \text {,b.e. }}$ of the LF solar field can be deduced for various storage capacities and for the two sites Daggett and Seville. $C_{\mathrm{SF}, \text { b.e. }}$ represent the highest specific cost of solar field of the LF system at which competitiveness with a comparable PT system is achieved.

As a basis we assume power block costs of $700 € / \mathrm{kW}$ and storage costs of $30 € / \mathrm{kWh}_{\mathrm{th}}$. The parabolic trough field costs are estimated to be $300 € / \mathrm{m}^{2}$ related to net aperture area (including foundations, levelling, HTF, and all components). It should be noted, that specific costs are assumed to be independent from the plant component size. Furthermore, a surcharge rate for construction of $20 \%$ is assumed. These $20 \%$ are added to the 
total equipment costs (which consist of SF, PB, TES and land costs). Financial parameters are listed in Table 7.1.

Table 7.1: Financial parameters

\begin{tabular}{|l|c|c|c|}
\hline & unit & PT & LF \\
\hline specific cost of SF & {$\left[€ / \mathrm{m}^{2}\right]$} & 300 & $200 \ldots 250$ \\
\hline specific cost of PB & {$\left[€ / \mathrm{kW}_{\mathrm{el}}\right]$} & \multicolumn{2}{|c|}{700} \\
\hline specific cost of TES & {$\left[€ / \mathrm{kWh}_{\mathrm{th}}\right]$} & \multicolumn{2}{|c|}{30} \\
\hline specific cost of land & {$\left[€ / \mathrm{m}^{2}\right]$} & \multicolumn{2}{|c|}{8} \\
\hline surcharges for construction & {$[\%]$} & \multicolumn{2}{|c|}{20} \\
\hline
\end{tabular}

\subsection{Results}

As already mentioned all examined solutions shall be equal in terms of annual electricity output. As reference we chose a PT plant with the following parameters: $\mathbf{S M}$ of $\mathbf{2}, \boldsymbol{P}_{\mathrm{el}, \mathrm{gross}}=\mathbf{5 0}$ $\mathrm{MW}, \boldsymbol{C}_{\mathrm{TES}}=8 \mathrm{FLH}$ in Daggett (all further parameters see Table 4.1 and 4.4) which achieves an annual net energy output $\boldsymbol{W}_{\text {net }}$ of $220 \mathbf{G W h}$. All other solutions, which are presented in this study, shall also achieve this energy output. However, the site, solar field size, gross electric power and storage capacity vary.

Fig 7.1 shows the net aperture area and the gross electrical power for a constant $W_{\text {net }}$ of all examined solutions for Daggett. Fig. 7.2 shows the CI of all solutions with a small storage capacity of 2 FLH, whereas Fig. 7.3 shows the same with a large storage capacity of 12 FLH. The SF cost of the PT is constant, while for the LF configurations, curves for SF costs between 200 and $250 € / \mathrm{m}^{2}$ are shown. Table 7.2 shows for each category of storage capacity the cost-optimal solution amongst the PT systems with constant $W_{\text {net }}$. Below, the cost-optimal LF solutions are shown, whose CI equals the CI of the PT system in the corresponding category of storage capacity. For these LF solutions the exact break-even costs $C_{\mathrm{SF} \text {,b.e. }}$ of the $\mathrm{SF}$ are listed. Furthermore, the percentual share of co-firing that is used for anti-freeze $\mathrm{COF}_{\mathrm{AF}}$ and for direct electricity production $\mathrm{COF}_{\mathrm{el}}$ is given.

The figures yield the following findings

I. Configurations with a large storage capacity (in FLH) need smaller solar fields and smaller power blocks to achieve the prescribed electrical yield of $220 \mathrm{GWh}$.

II. By examining a set of configurations with constant storage capacity, as for example a PT system with a storage capacity of 2 FLH (TES 2), it becomes clear that with different combinations of $\mathrm{PB}$ and storage capacity, a constant $W_{\text {net }}$ can be achieved. For the determination of the preferable solution economic figures must be taken into account

III. In order to compensate the inferior optical performance (as described in the previous sections), with the same number of FLH of storage capacity, the LF field must be much larger compared to the PT field (for example the $A_{\text {net }}$ of the LF configurations with 2 FLH exceeds the ones of the PT configurations of about $40 \%$.

IV. The nominal electrical power of the power block is also slightly higher for the LF systems then for the PT systems in each category of storage capacity

V. Regarding Fig. 7.2 and 7.3 one notices that for each configuration there is cost-optimum with a specific SM. These characteristics can be explained with the following two phenomena: By under-sizing the SF (low SM) the storage system will be charged less often, and hence, the PB operating hours decrease. By over-sizing the SF (high SM) the increase in energy yield saturate and more solar energy must be dumped. Consequently, the increasing costs for the solar field are economically not justified, anymore.

VI. The cost optimum (the lowest CI cost) of the LF systems generally is attained with greater SM than the one of the PT systems. This phenomenon is also due to the optical characteristics.

VII. With increasing storage capacities, the CI of the PT system decreases, attaining its minimum with a storage capacity of $12 \mathrm{FLH}$. The CI of systems with a capacity of 14 FLH begins to increase again, since especially in summer the storage system cannot be discharged anymore during the shorter nights. Hence, the degree of utilization decreases and the investment costs for the large storage system are economically not justified. However, it should be noted that the result is only valid for constant feed-in-tariff.

VIII. Generally, due to lower heat losses the Fresnel system needs a smaller share of the allowed co-firing energy ( $15 \%$ of total thermal energy yield) for antifreeze operation $Q_{\text {cof,AF. The remaining energy from }}$ co-firing can directly be used for electricity production.

IX. The break-even costs of the SF of the LF system with solar salt in relation to the PT system range from $201.6 € / \mathrm{m}^{2}$ at $0 \mathrm{FLH}$ to $221.3 € / \mathrm{m}^{2}$ at $14 \mathrm{FLH}$. Regarding the cost-optimal PT solution (12 FLH), the break-even cost of the corresponding LF solar field would be $217.8 € / \mathrm{m}^{2}$. Apparently, a Fresnel system without TES is especially penalized by the daily course of the optical efficiency (see section 5). With the implementation of a small TES system (2 FLH), this disadvantage is compensated. Large storage capacities tend to favour LF solutions. 


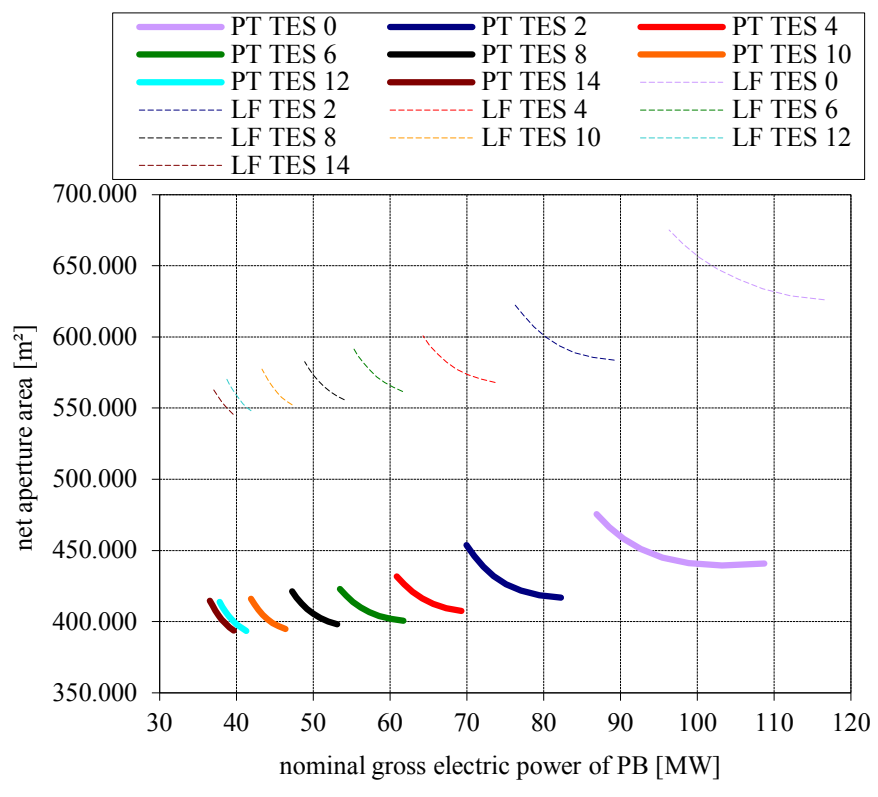

Figure 7.1: Plant configurations of PT and LF with $W_{\text {net }}=220 \mathrm{GWh}$, Daggett

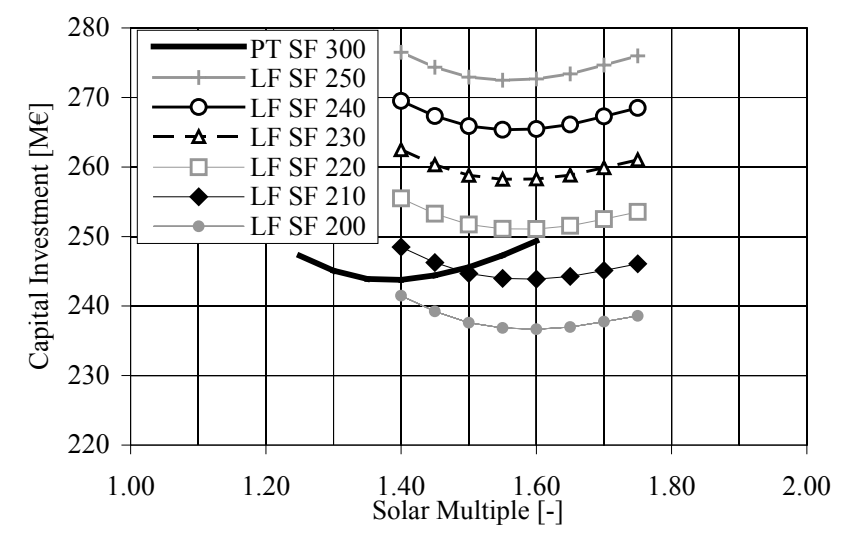

Figure 7.2: $\mathrm{Cl}$ of both systems for $2 \mathrm{FLH}, W_{\text {net }}=220 \mathrm{GWh}$ GWh Daggett

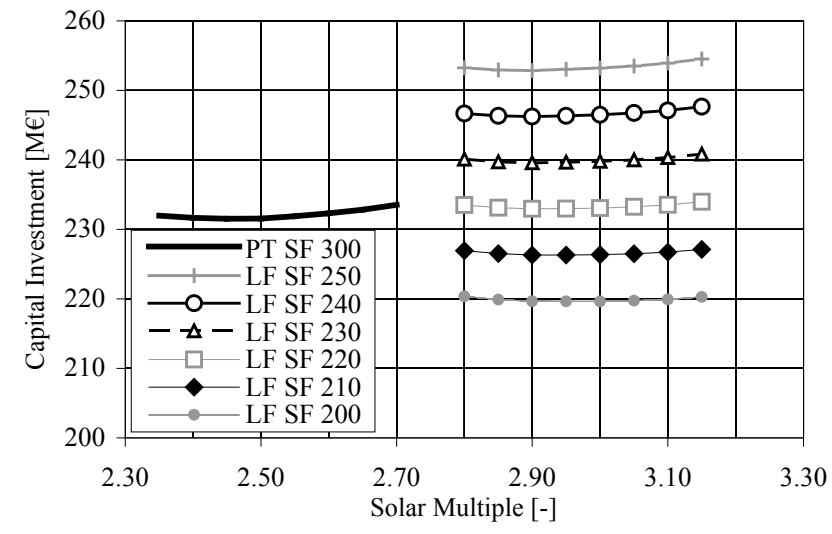

Figure 7.3: $\mathrm{Cl}$ of both systems for $12 \mathrm{FLH}$ and annual output of 220 GWh, Daggett.
Table 7.2: Cost-optimal configurations for a given storage capacity, $W_{\text {net }}=220 \mathrm{GWH}$, Daggett

\begin{tabular}{|c|c|c|c|c|c|c|c|c|c|}
\hline \multicolumn{2}{|c|}{ parab. Trough } & \multicolumn{8}{|c|}{ storage capacity [FLH] } \\
\hline$C_{\mathrm{TES}}$ & {$[\mathrm{FLH}]$} & 0 & 2 & 4 & 6 & 8 & 10 & 12 & 14 \\
\hline CI & [M€] & 255.3 & 243.8 & 239.7 & 237.4 & 235.9 & 232.8 & 231.5 & 235.6 \\
\hline$A_{\text {net }}$ & {$\left[10^{3} \mathrm{~m}^{2}\right]$} & 445.0 & 426.3 & 416.2 & 409.9 & 405.5 & 401.7 & 398.0 & 398.6 \\
\hline $\mathrm{COF}_{\mathrm{AF}}$ & {$[\%]$} & 43 & 43 & 42 & 42 & 42 & 43 & 42 & 43 \\
\hline $\mathrm{COF}_{\mathrm{el}}$ & {$[\%]$} & 57 & 57 & 58 & 58 & 58 & 57 & 58 & 57 \\
\hline$P_{\text {gross }}$ & [MW] & 95.4 & 75.1 & 64.2 & 56.2 & 50.0 & 44.0 & 40.1 & 38.6 \\
\hline $\mathrm{SM}$ & {$[-]$} & 1.15 & 1.40 & 1.60 & 1.80 & 2.00 & 2.25 & 2.45 & 2.55 \\
\hline \multicolumn{2}{|c|}{ linear Fresnel } & \multicolumn{8}{|c|}{ storage capacity [FLH] } \\
\hline$C_{\mathrm{TES}}$ & {$[\mathrm{FLH}]$} & 0 & 2 & 4 & 6 & 8 & 10 & 12 & 14 \\
\hline CI & {$[\mathrm{M} €]$} & 255.3 & 243.8 & 239.7 & 237.4 & 235.9 & 232.8 & 231.5 & 235.6 \\
\hline$A_{\text {net }}$ & {$\left[10^{3} \mathrm{~m}^{2}\right]$} & 647.7 & 600.0 & 582.4 & 572.0 & 564.9 & 560.9 & 553.2 & 553.6 \\
\hline $\mathrm{COF}_{\mathrm{AF}}$ & {$[\%]$} & 12 & 12 & 12 & 12 & 12 & 12 & 12 & 12 \\
\hline $\mathrm{COF}_{\mathrm{el}}$ & {$[\%]$} & 88 & 88 & 88 & 88 & 88 & 88 & 88 & 88 \\
\hline$P_{\text {gross }}$ & [MW] & 102.6 & 80.2 & 67.4 & 58.3 & 51.4 & 45.3 & 40.8 & 38.2 \\
\hline SM & {$[-]$} & 1.35 & 1.60 & 1.85 & 2.10 & 2.35 & 2.65 & 2.90 & 3.10 \\
\hline$C_{\text {SF,b.e. }}$ & {$\left[€ / \mathbf{m}^{2}\right]$} & 201.6 & 209.9 & 213.0 & 214.9 & 216.2 & 215.7 & 217.8 & 221.3 \\
\hline
\end{tabular}

In the following the same analyses are carried out for Seville, where also $220 \mathrm{GWh}$ of annual yield serves as reference. Fig. 7.4 shows the plant layouts of both systems, with constant $W_{\text {net }}$ and varying storage capacities. Fig. 7.5 and 7.6 show the CI of all solutions for 2 FLH and 12 FLH respectively. Table 7.3 shows the cost-optimal PT and LF solutions with the break-even cost of solar field of the LF system. Additionally, the percentual increase of CI costs for Seville compared to Daggett is presented. In fact, the meteorological conditions penalize Seville compared to Daggett - compare with section 4.4. If the same annual electricity yield is to be achieved, the plant must be significantly greater compared to the plant in Daggett, which increases the CI costs.

From the figures the following additional conclusions are drawn:

$\mathrm{X}$. The inferior irradiation conditions in Seville moves the cost-optimal solution of both system towards higher SM (e.g. PT with 12 FLH, Daggett: 2.5; PT with 12 FLH, Seville: 2.95 )

XI. Regarding the PT system, in order to achieve the same $W_{\text {net }}$ the plant size must be adapted, and hence, the $\mathrm{CI}$ increases by $55-59 \%$.

XII. Due to the inferior meteorological conditions in Seville (see section 4.4), the solar field is more often in anti-freeze mode. This penalizes especially the PT systems, which consumes about $80 \%$ of its allowed co-firing energy directly for anti-freeze operation. The LF systems are less affected, since the heat losses of the solar field are much lower. Hence, more 
thermal energy from co-firing can be consumed for electricity production.

XIII. Due anti-freeze issue, compared to the PT system, the LF system performs better in Seville than in Daggett. Hence, the break-even costs of the Solar Salt LF solar field are higher in Seville: 223.6 for $0 \mathrm{FLH}$ and $234.5 € / \mathrm{m}^{2}$ for $12 \mathrm{FLH}$. In other words, the LF system is favoured by the site

XIV. As for Daggett, LF systems are favoured by large storage capacities

Here, it must be mentioned that the advantage for the LF system in Seville occurs in the case of Solar Salt, since the antifreeze temperature in the plant is very high. With another heat transfer fluid, this advantage might not be crucial. Furthermore, the present study does not answer the question of general costeffectiveness of line-focusing salt systems in Seville compared to other systems (such as DSG and synthetic oil).

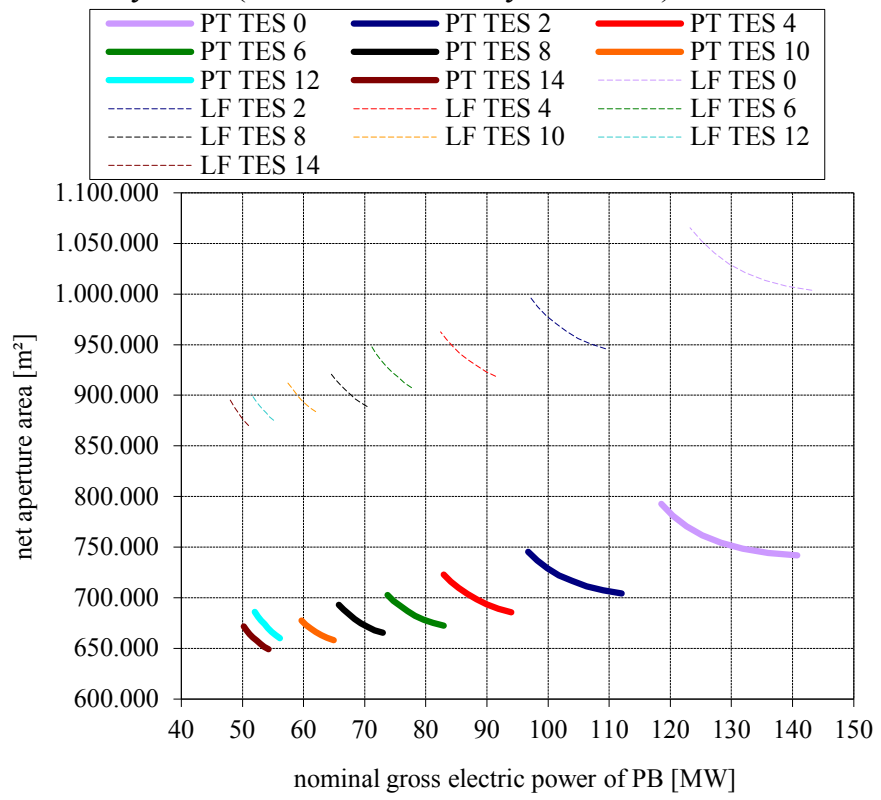

Figure 7.4: Plant configurations of PT and LF with $W_{\text {net }}=220 \mathrm{GWh}$, Seville.

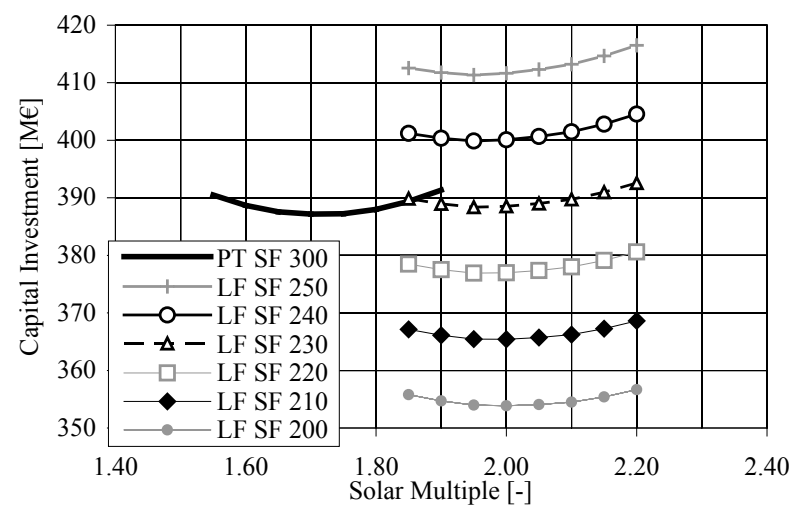

Figure 7.5: $\mathrm{Cl}$ of both systems for $2 \mathrm{FLH}$, $W_{\text {net }}=220 \mathrm{GWh}$, Seville.

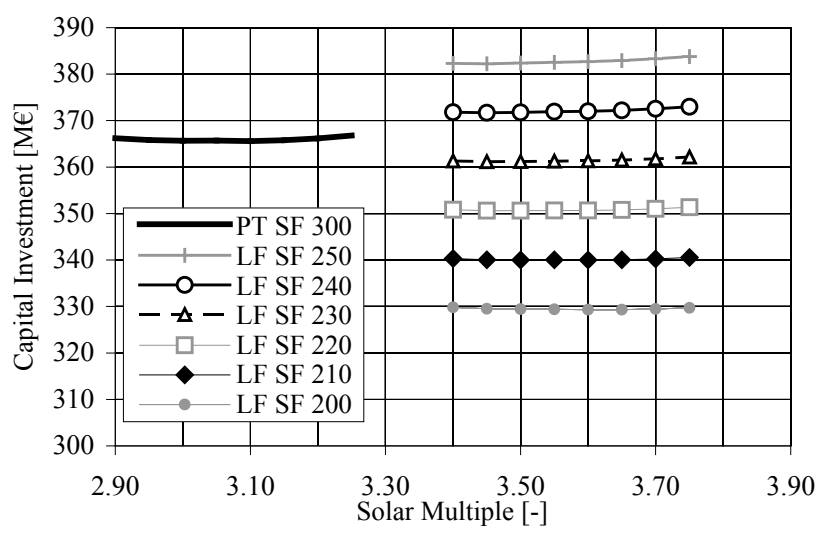

Figure 7.6: $\mathrm{Cl}$ of both systems for $12 \mathrm{FLH}$, $W_{\text {net }}=220 \mathrm{GWh}$, Seville.

Table 7.3: Cost-optimal configurations for a given storage capacity, $W_{\text {net }}=220 \mathrm{GWH}$, Seville

\begin{tabular}{|c|c|c|c|c|c|c|c|c|c|}
\hline \multicolumn{2}{|c|}{ parab. Trough } & \multicolumn{8}{|c|}{ storage capacity [FLH] } \\
\hline$C_{\mathrm{TES}}$ & {$[\mathrm{FLH}]$} & 0 & 2 & 4 & 6 & 8 & 10 & 12 & 14 \\
\hline $\mathrm{CI}$ & {$[\mathrm{M} €]$} & 404.7 & 387.2 & 379.4 & 374.6 & 371.5 & 367.4 & 364.5 & 365.6 \\
\hline$D_{\mathrm{CI}, \text { Dag. }}$ & {$[\%]$} & 58.5 & 58.8 & 58.3 & 57.8 & 57.5 & 57.8 & 57.5 & 55.2 \\
\hline$A_{\text {net }}$ & {$\left[10^{3} \mathrm{~m}^{2}\right]$} & 128.3 & 716.5 & 698.5 & 682.4 & 675.0 & 669.7 & 663.0 & 660.7 \\
\hline $\mathrm{COF}_{\mathrm{AF}}$ & {$[\%]$} & 81 & 80 & 79 & 78 & 80 & 79 & 79 & 79 \\
\hline $\mathrm{COF}_{\mathrm{el}}$ & [\%] & 19 & 20 & 21 & 22 & 20 & 21 & 21 & 21 \\
\hline$P_{\text {gross }}$ & [MW] & 128.3 & 103.9 & 88.3 & 78.3 & 69.4 & 61.2 & 55.4 & 51.7 \\
\hline SM & {$[-]$} & 1.45 & 1.70 & 1.95 & 2.15 & 2.4 & 2.70 & 2.95 & 3.15 \\
\hline \multicolumn{2}{|c|}{ linear Fresnel } & \multicolumn{8}{|c|}{ storage capacity [FLH] } \\
\hline$C_{\mathrm{TES}}$ & {$[\mathrm{FLH}]$} & 0 & 2 & 4 & 6 & 8 & 10 & 12 & 14 \\
\hline $\mathrm{CI}$ & {$[\mathrm{M} €]$} & 404.7 & 387.2 & 379.4 & 374.6 & 371.5 & 367.4 & 364.5 & 365.5 \\
\hline$A_{\text {net }}$ & {$\left[10^{3} \mathrm{~m}^{2}\right]$} & 1020.8 & 956.2 & 929.2 & 912.1 & 896.3 & 890.6 & 878.5 & 873.3 \\
\hline $\mathrm{COF}_{\mathrm{AF}}$ & [\%] & 25 & 24 & 24 & 24 & 24 & 24 & 24 & 24 \\
\hline $\mathrm{COF}_{\mathrm{el}}$ & [\%] & 75 & 76 & 76 & 76 & 76 & 76 & 76 & 76 \\
\hline$P_{\text {gross }}$ & [MW] & 132.4 & 104.9 & 88.4 & 76.5 & 68.5 & 60.5 & 54.5 & 50.5 \\
\hline SM & {$[-]$} & 1.7 & 2.0 & 2.3 & 2.6 & 2.8 & 3.2 & 3.5 & 3.7 \\
\hline$C_{\mathrm{SF}, \mathrm{b} . \text {-e. }}$ & {$\left[€ / \mathbf{m}^{2}\right]$} & 223.6 & 228.9 & 230.6 & 231.6 & 232.2 & 231.7 & 233.2 & 234.5 \\
\hline
\end{tabular}




\section{CONCLUSIONS}

In the present publication, in a first step, the optical and the thermodynamic characteristics of a PT and LF solar field with Solar Salt have been compared. While the optical performance of the LF system cannot match the one of the PT system, heat losses of the Fresnel system are lower due to a smaller number of absorber tubes and a more compact solar field. However, the overall thermodynamic performance of the solar field is lower.

In a second step the annual performance of typical PT and LF plant configurations with 0 to 14 FLH of storage capacity have been compared. The annual electricity yield of various plant configurations has been calculated with a thermodynamic plant model for two sites, Daggett, CA, US and Seville, Spain. As boundary conditions the Spanish market with a constant feed-in-tariff and $15 \%$ annual co-firing has been chosen. All examined configurations achieve the same net electricity yield of $220 \mathrm{GWh}$ per year.

Results show, that a linear Fresnel system can be implemented in the same thermodynamic process as a parabolic trough system and the same annual electricity yield can be attained. In terms of annual yield the disadvantage of optical performance of the Fresnel system can be compensated by oversizing the solar field. Generally, both systems tend to be more cost-effective with large storage capacities. At both sites, the cost optimum is achieved with a storage capacity of 12 full load hours. In order to judge the competitiveness of Fresnel systems, the break-even costs of solar field have been calculated. Solar field costs for the parabolic trough system with Solar Salt of $300 € / \mathrm{m}^{2}$ have been assumed. Generally, with large storage capacities break-even costs of the LF solar field rise; this means that the competitiveness of LF increases. The break-even costs for Daggett range between $202 € / \mathrm{m}^{2}(0 \mathrm{FLH})$ and $221 € / \mathrm{m}^{2}(14$ FLH), or 67 to $74 \%$ of the parabolic trough field. For Seville the break-even cost range between $224 € / \mathrm{m}^{2}(0 \mathrm{FLH})$ and 235 $€ / \mathrm{m}^{2}$ (14 FLH), or 75 to $78 \%$. The site-specific advantage of the LF system is due to the lower heat losses, necessitating less co-firing for anti-freeze operation. Nevertheless, it must be noted, that this advantage is specific for plants with Solar Salt and would not necessarily occur with other heat transfer fluids with significantly lower anti-freeze temperature. Eventually, for both sites the highest break-even costs of the LF solar field compared to the PT solar field is achieved with large storage capacities.

\section{REFERENCES}

[1] Morin, G., Dersch, J., Eck, M., et al., 2011, "Comparison of Linear Fresnel and Parabolic Trough Collector power plants," Solar Energy, pp. 12.

[2] Dersch J., M. G., Eck M., Häberle A.,, 2009, "Comparison of linear Fresnel and parabolic trough collecor systems - system analysis to determine breakeven costs of linear fresnel collectors," SolarPaces 2009, Berlin.
Giostri, A., Binotti, M., Silva, P., et al., 2011, "Comparison of two Linear Collectors in solar thermal Plants: Parabolic Trough vs. Fresnel," ASME 2011 5th International Conference on Energy Sustainability, Washington, DC, USA.

[4] Winter, C. J., Sizmann, R. L., and Vant-Hull, L. L., 1991, Solar Power Plants - Fundamentals Technology - Systems - Economics, Springer Verlag, Berlin, Heidelberg.

[5] Solarlite, 2011, "Press release: TSE 1 - The first parabolic trough plant using direct steam generation delivers its full $5 \mathrm{MW}$ of output to Thailand's power network " 2011-01-26.

[6] Eck, M., Eickhoff, M., Feldhoff, J. F., et al., 2011, "Direct Steam Generation in parabolic troughs at $500^{\circ} \mathrm{C}$ - First results of the REAL-DISS project," 17 th SolarPACES, Granada, Spain.

[7] Selig, M., and Mertins, M., 2010, "From Saturated to Superheated Direct Solar Steam Generation Technical Challenges and Economical Benefits," 16th SolarPaces, Perpignon, pp. 8.

[8] Novatec Solar, 2011, "Press release: Novatec Solar's Fresnel collector generates superheated steam above $500^{\circ} \mathrm{C}, "$ 2011-09-11.

[9] Fernández-García, A., Zarza, E., Valenzuela, L., et al., 2010, "Parabolic-trough solar collectors and their applications," Renewable and Sustainable Energy Reviews, 14, pp. 1695 - 1721.

[10] Lüpfert, E., 2005, "PARFOR - Testreport PTR Parabolic Trough Receiver 2005 - Modelling Parameters from Test Results," Technical Report DLR, Cologne.

[11] Burkholder, F., and Kutscher, C., 2009, "Heat loss testing of Schott's 2008 PTR70 Parabolic Trough Receiver " Technical Report NREL/TP-550-45633, National Renewable Energy Laboratory,

[12] Schott Solar, 2011, "Schott PTR 70 Receiver - Setting the Benchmark."

[13] Conlon, W. M., 2011, "Direct Steam from CLFR Solar Steam Generators," 17th SolarPACES, Granada, Spain.

[14] Eck, M., Bernhard, R., De Lalaing, J., et al., 2009, "Linear Fresnel Collector Demonstration at the PSA Operation and Investigation," R. Pitz-Paal, eds., 15th CSP SolarPACES Symposium, Berlin, Germany.

[15] Novatec Solar, 2011, "Nova-1 - Turnkey solar boiler, mass produced in industrial precision - with performance guarantee."

[16] NREL, 2012, http://www.nrel.gov/rredc/.

[17] Meteotest, 2012, http://meteonorm.com.

[18] Kearney, D., Herrmann, U., Nava, P., et al., 2003, "Assessment of a Molten Salt Heat Transfer Fluid in a Parabolic Trough Solar Field," Journal of Solar Energy Engineering, 125 (2), pp. 170-176. 